\title{
Mermerlerin Aşınma Direncini Belirlemek İçin Kullanılan Geniş Diskli Așındırma Testi (GDA) İçin Bazı Yorumlar ve Öneriler
}

Some Comments and Suggestions for Wide Wheel Abrasion Test Used to Determine the Abrasion Resistance of Marbles

\author{
Ali ÖZVAN 1 (D), Ercan INAN ${ }^{2}$ (D) \\ ${ }^{1}$ Van Yüzüncü Yll Üniversitesi, Jeoloji Mühendisliği Bölümü, Van \\ ${ }^{2}$ Van Yüzüncü Yll Üniversitesi, Fen Bilimleri Enstitüsü, Van
}

Geliş (Received): 03 Şubat (February) 2020 / Düzeltme (Revised): 25 Nisan (April) 2020 / Kabul (Accepted): 10 Temmuz (July) 2020

ÖZ

Mermerlerin aşınmasını belirlemek için en çok kullanılan standart deney yöntemleri, Geniş Disk (Dikey) Aşındırma (GDA) ve Böhme Aşındırma (BA) deneyleridir. Bu çalışmada, GDA deneyinde uygulanan karşı ağırlık yüklerin, cilalı ve mat yüzeyli örnek yüzeylerin ve farklı aşındırıcı tozların test sonuçları üzerindeki etkisinin belirlenmesi amaçlanmıştır. Bu çalışmada, GDA deneyi için 48 adet 7x10x3 cm boyutlarında ve BA deneyi için 24 adet $7 \times 7 \times 3 \mathrm{~cm}$ boyutlarında numune kullanılmışır. Deneylerin sonucunda, mermer numunelerin mat yüzeylerinin aşınma deneylerinde daha doğru sonuçlar verdiği tespit edilmiştir. GDA ve BA deneylerinde hem siyah renkli yapay korundum hem de beyaz erimiş alümina korundum tozu kullanıldığında örnekler üzerinde birbirine yakın aşındırma değerleri elde edilmiştir. Ayrıca, GDA deneyinde numunenin anizotropisinin önemli olduğu ve sıkıştırma ağırlığının da oluk şeklini etkilediği deneyler sonucunda belirlenmiştir.

Anahtar Kelimeler: Mermer, Aşınma Direnci, Geniş Diskli Aşındırma Deneyi, Böhme Aşındırma Deneyi, Aşındırıcı Toz, S1kıştırma Ağırlı̆̆ 1

\section{ABSTRACT}

The most widely used standard test methods for determining wear of the marbles are Wide Wheel (Vertical) Abrasion (WWA) and Böhme Abrasion (BA) tests. In this study, it was aimed to determine the effect of the counterweight loads applied in the WWA experiment, sample surfaces with polished and matte surfaces and different abrasive powders on the test results. In this study, a total of $48(7 \times 10 \times 3 \mathrm{~cm})$ samples were used for the WWA tests and $24(7 \times 7 \times 3 \mathrm{~cm})$ samples were used for the BA tests. As a result of the experiments, it was determined that the matte surfaces of the marble samples reveal more accurate results in the abrasion tests. When both artificial corundum and corundum (white fused alumina) powder are used in WWA and BA experiments, similar abrasion values are obtained on the samples. In addition, it is determined in the WWA experiment that the anisotropy of the sample is important and the counterweight affects the groove shape.

Keywords: Marble, Abrasion Resistance, Wide Wheel Abrasion Test, Böhme Abrasion Test, Abrasive Powder, Counterweight 


\section{GíRiș}

Doğal taşların kaplamalarda ve anıtlarda kullanılabilmesi için fiziksel ve mekanik özelliklerinin yanı sıra doğal veya yapay ortamlardaki aşınma değerlerinin de bilinmesi gerekmektedir. Yap1 sektöründe kullanılan bu kaya malzemelerin aşınma kaybı miktarı malzemenin ömrünü etkileyen en önemli parametredir. Aşınma kaybı, yapı malzemesi olarak kullanılan taşların dış etkiler (atmosferik, araç ve insan vb.) sonucunda yüzeylerinde oluşan kayıp miktarının bir ifadesidir. Özellikle ıslanmakuruma, donma-çözülme ve tuz kristallenmesi gibi doğal olaylar ile araç ve insan gibi hareketli yükler, doğal kaya malzemelerin yıpranmasına ve özelliklerinin kaybolmasına neden olmaktadır. Doğada farklı özelliklere sahip kayaların bulunması nedeniyle doğru malzemelerin seçimi önemlidir. Doğal kaya malzemelerin yapılarda kullanılabilmesi için aşınma etkisine karşı performansının belirlenmesi amacıyla bazı deneylere tabi tutulması gerekmektedir. Farklı deney yöntemleri ile kayaların aşınma miktarları belirlense de, uzun yıllardır kullanılan Böhme Aşındırma Deneyi (BA) ile son yıllarda kullanımı yaygınlaşan Geniş Diskli (Dikey) Aşındırma Deneyi (GDA) yaygın olarak kullanılan deneylerin başında gelmektedir.

Doğal taşlardaki aşınma kaybı miktarının farklı kayalarda ve farklı deneyler ile belirlenmesine yönelik birçok çalışma bulunmaktadır. Özellikle BA ve GDA deney yöntemleri üzerine yapılan çalışmalar incelendiğinde, genelde son yıllarda GDA deneyinin sıklıkla kullanılmasına bağlı olarak bu iki deneyi birlikte değerlendiren çalışmaların arttığı gözlenmektedir. Bu çalışmaların temelinde uzun yıllardır kullanılan ve sonuçlarına ilişkin birçok çalışmanın olduğu bilinen BA deneyine alternatif olacak GDA deneyinin sonuçlarının
BA deneyi ile karşılaştırılması yatmaktadır. Geçmişten günümüze kayalardaki aşınma ve bu aşınma miktarlarının belirlendiği deneylerle ilişkili çalışmalar incelendiğinde, McGregor ve Chiu (2000), kayaçların aşınmaları ve sertlikleri arasındaki ilişkileri incelemek için mermer ve granit örnekleri üzerinde çalışmış ve araştırma sonucunda aşınma ile sertlik arasında bir logaritmik ilişkinin olduğunu belirlemişlerdir. Sahlin vd. (2001), kireçtaş1 örnekleri üzerinde aşınma deneyleri yapmış ve GDA deneyinin değerlendirilmesinde kısıtlı çalışma olduğunu ve geliştirilmesi gerektiğini önermişlerdir. Karaca vd. (2010), beş farklı doğal kayacın donma-çözülme döngüsünden önceki $\mathrm{BA}$ ve GDA deneyi değerlerini araştırmışlardır. BA ve GDA yöntemlerinin, mermerler, kireçtaşları ve travertenlerin aşınma değerlerinin tespit edilmesinde kullanılabileceğini ancak, oniks ve granitin aşınma değerlerinin tespit edilmesi için uygun olmadığını ortaya koymuşlardır. Çobanoğlu ve Çelik (2010), kireçtaşı, mermer, dolomitik kireçtaşı ve traverten numuneleri üzerinde BA ve GDA deneyi sonuçlarını değerlendirmişler ve karbonat bileşimli kayalar için GDA (mm) ve BA ( $\mathrm{cm}^{3}$ cinsinden) arasında lineer bir denklem önermişlerdir. Marini vd. (2011), GDA deneyinde aşındırıcı malzemenin (korundum) etkin kullanımı ve kalibrasyonu için test edilen Boulonnais Mermeri yerine değişik taşlarla kalibrasyonun uygulanabilirliğini araştırmışlardır. Ayrıca aşınma deneyinde kullanılan aşındırıcı malzemenin üç defa kullanılabileceğini öne sürmüşlerdir. Karaca vd. (2012), tortul, metamorfik ve magmatik kökenli 25 farklı doğal taş örneği kullanarak BA ve GDA deneyi sonuçları arasındaki ilişkileri incelemiştir. Test edilen numunelerin aşınma direncinin yanı sıra fiziksel ve mekanik özellikleri incelenmiş ve BA ile GDA deneyi sonuçları arasında doğrusal tekliregresyon ilişkisi elde etmişlerdir. Çobanoğlu 
ve Çelik (2017), BA deney prosedürünün pratik olmamasından dolayı daha kolay ve ekonomik aşınma yöntemi olan GDA sonuçlarının tahmin edilmesini amaçlamıştır. Bahsi geçen çalışmada, 32 doğal taş örneğinin bazı fiziksel özellikleri, sertlik değerleri, GDA, BA ve tek eksenli basınç dayanım değerleri belirlenmiş ve bu değerler arasındaki ilişkiler incelenmiştir.

Bilindiği gibi, GDA ve BA deneyleri taş yüzeyine farklı yönlerde ve farklı yüklerde uygulanarak taşın aşınma miktarının belirlenmesi üzerine kurgulanmışlardır. BA deneyinde $7 \times 7 \mathrm{~cm}$ yüzey alanına sahip prizmatik veya kübik ölçülerdeki taşın tüm yüzeyi aşınmaya maruz kalırken, GDA deneyinde taşın yaklaşık $2 \mathrm{~cm}$ genişliğindeki bir yüzeyi aşınmaya maruz kalmaktadır. $\mathrm{Bu}$ deneylerin uygulamasında sonuçları etkileyecek şekilde, taşın anizotropisi, mat veya cilalı oluşu, aşındırıcı toz temini ve miktarı ile aşındırıcı yüzey ve diske bağlı olarak bazı problemlerle karşılaşılmaktadır. GDA deneyinde taş ile aşındırma diskinin temasının tam olarak sağlanması önemlidir. Bunun için standartta (TS EN 14157, 2017) yaklaşı 14 kg bir sıkıştırma ağırlığı ile taşın çekilerek diske teması sağlanmaktadır. Özellikle taşın geniş disk üzerine tam olarak temas etmediği durumlarda, taş yüzeyinin tamamında yaklaşık aynı genişlikte bir oluk oluşmamaktadır. $\mathrm{Bu}$ durum, GDA deneyinden aşınmanın belirlenmesinde bir engel oluşturabilmektedir. Aşındırma deneylerinde çalışmaciya engel olan diğer bir sorun da aşındırıcı tozların miktar ve maliyetidir. Her iki deney standardında farklı özelliklerde aşındırma tozları önerilmektedir. $\mathrm{Bu}$ aşındırma tozlarının temini özel firmalar tarafindan yurtdışından sağlanmaktadır. Bu nedenle maliyetleri yüksek olabilmektedir.

Yukarıda bahsedilen sorunlar dikkate alındığında, son yıllarda kullanımı artan GDA deneyinin uygulanmasındaki teknik, ekonomik ve malzeme şartlarının engelleyici durumlarının belirlenmesi amacıyla bu çalışma yapılmıştır. GDA deneyindeki sorunların tartışılabilmesi için benzer bir deney olan BA deneyi ile birlikte çalışma yürütülmüş ve sonuçlar karşılaştırılmıştır. $\mathrm{Bu}$ çalışmanın ana amaçları, farklı mineraloji, bileşim ve doku özelliklerine sahip mermerlerde;

- GDAdeneyiiçinörneklerüzerindeuygulanan farklı sıkıştırma ağırlıklarının aşındırma oluklarındaki etkisinin belirlenmesi,

- Cilalı ve mat yüzlere sahip mermerlerde GDA deneyi sonrasındaki aşınma farklılıklarının ve cilalanmanın aşındırma deneyine etkisinin olup olmadığının belirlenmesi,

- Aşınma deneylerinde kullanılan farklı aşındırıcı tozların GDA deneyi aşındırma sonuçları üzerindeki etkisinin belirlenmesidir.

$\mathrm{Bu}$ amaçlar doğrultusunda mermer olarak en çok tercih edilen 4 farklı özelliğe sahip kaya örneği seçilmiştir. Örnekler çalışmanın yapıldığ1 bölgedeki bir mermer fabrikasından elde edilmiştir. Deneyler için kullanılan mermer örneklerinin bir yüzeyi cilalı diğer yüzeyi ise mat olacak şekilde standartlarda istenilen boyutlarda kestirilerek hazırlanmıştır.

\section{MALZEME VE YÖNTEM}

$\mathrm{Bu}$ çalışmanın yapılması aşamasında materyal olarak, farklı özelliğe sahip üç adet kireçtaşı (Tusba Bej, Tamara Bej, Rosavera) ve bir adet granit (Diana Granit) olmak üzere toplam dört farklı kaya örneği kullanılmıştır. Örnekler bölgedeki bir mermer fabrikasından elde edilmiştir ve GDA deneyinde farklı sonuçlar verebilecek kayalar seçilmiştir. Deneysel araştırmaya dayalı bu çalışmada, ilk aşamada kesme ve düzeltme diskleri, boyutların 
Özvan, İnan

belirlenebilmesi için kumpas, hassas terazi, saf su ve etüv kullanılmıştır.

Çalışma konusu kapsamında 4 farklı kaya malzemesine ait prizmatik numuneler TS EN 14157 (2017) standardına uygun olarak kesilip hazırlanmıştır. Deneyler için 48 adet yaklaşık $7 \times 10 \times 3 \mathrm{~cm}^{3} \quad$ (GDA Standard1) ve 24 adet yaklaşık $7 \times 7 \times 3 \mathrm{~cm}^{3}$ (BA Standardı) boyutlarında mermer örneği hazırlanmıştır. Mermer örnekleri fabrikadaki satış aşamasından alındığından dolayı örneklerin bir yüzü cilalı diğer yüzü mat özelliğe sahiptir (Şekil 1). Böylece cilalı yüzeylerin aşınma üzerindeki etkisi de ayrıca incelenmiştir.

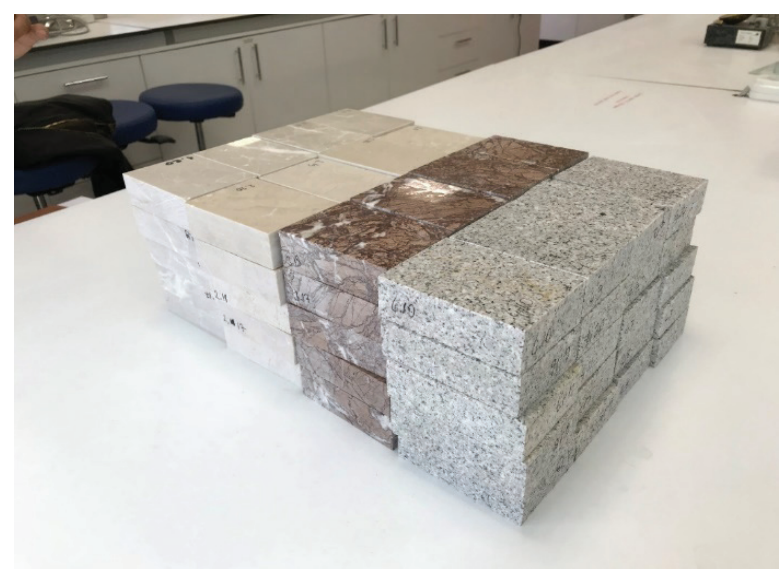

tozu kullanılmıştır. Her iki toz maliyet açısından karşılaştırıldığında, BA deneyinde kullanımı önerilen siyah renkli yapay korundum aşındırma tozunun birim fiyatının GDA deneyinde kullanılan beyaz erimiş alümina korundum tozunun birim fiyatının yaklaşık üç katı kadar olduğu tespit edilmiştir.

Seçilen kaya örnekleri ve belirlenen deney yöntemleri sonrasında laboratuvar çalışmalarına geçilmiştir. Laboratuvar çalışmalarının ilk aşamasında seçilen kayaların fiziksel özellikleri TS 699 (2016) standardına göre belirlenmiştir ve kaya örneklerinin kuru ağırlıkları ile saf suda 48 saat bekletildikten sonraki doygun ağırlıkları

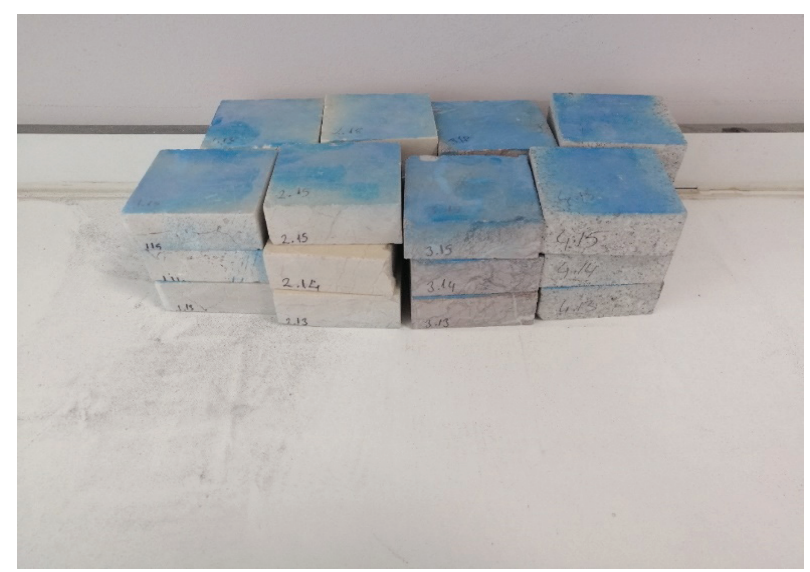

Şekil 1. Deneylerde kullanılan dikdörtgen ve kare yüzey alanına sahip örneklere ait bir görüntü.

Figure 1. An image of the samples with rectangular and square surface area used in the experiments.

Bu çalışmanın ana amacı GDA deneyindeki sorunlara bir yaklaşımda bulunmaktır. Bu amaç doğrultusunda GDA deneyinin sonuçlarının BA deneyi ile karşılaştırılması hedeflenmiştir. GDA ve BA deneylerinde (TS EN 14157, 2017) farklı özelliğe sahip aşındırma tozları kullanılmaktadır (Şekil 2). BA deneyinde $1.10 \mathrm{~mm}$ ile $5.10 \mathrm{~mm}$ aşınma üretmek için tasarlanmış siyah renkli yapay korundum kullanılmıştır. GDA deneyinde ise, beyaz renkli FEPA 42-1: 2006 teknik belgesine uygun olarak, büyüklüğü 80 (201 $\mu \mathrm{m})$ olan korundum (beyaz erimiş alümina) tespit edilmiştir. Daha sonra numunelerin mat ve cilalı yüzeyleri üzerinde GDA ve BA deneyleri TS EN 14157 (2017) standardında belirtilen cihazlar (Şekil 3) ve tozlar ile belirtilen yöntem sırasına göre yapılmıştır. Bu çalışmanın amaçlarından biri olan, farklı aşındırma tozlarının GDA sonuçları üzerindeki etkisinin belirlenmesi amacıyla, GDA ve BA deneylerinde hem beyaz erimiş alümina korundum hem de siyah renkli yapay korundum kullanılmış ve her iki deney sonundaki aşındırma farkları karşılaştırılmıştır. 

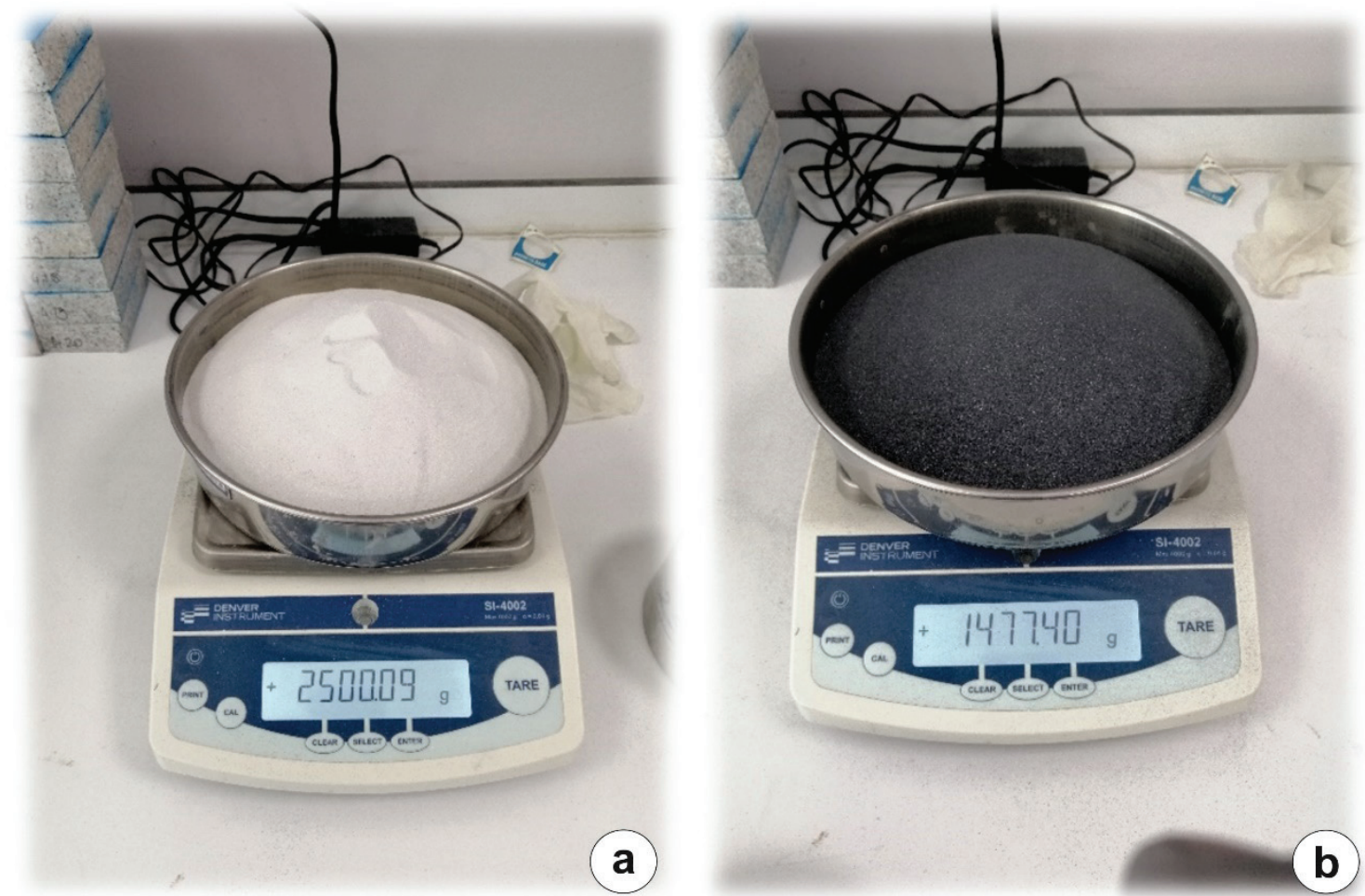

Şekil 2. Deneylerde kullanılan aşındırma tozlarına ait bir görüntü: (a) beyaz erimiş alümina korundum (GDA standard1), (b) siyah renkli yapay korundum (BA standard1).

Figure 2. An image of the abrasive powders used in the experiments: (a) white fused alumina corundum (GDA standard), (b) black artificial corundum(BA standard).

Bu çalışmanın diğer bir amacı doğrultusunda, GDA deneyinde farklı sıkıştırma yüklerinin oluk açıklı̆̆ı üzerindeki etkisini belirlemek amaciyla, deney standardında önerilen beyaz renkli alüminalı korundum tozu kullanılarak, oluk açıklığının değişimi tespit edilmiştir. GDA deneyinde aşınma direncinin oluk açıklığından belirlenmesinde gözlenen ilk problem, oluğun taşın her noktasında her zaman düzgün oluşmamasından kaynaklı hatalı sonuçların elde edilmesidir. Taşın disk üzerine tam temas edememesi, disk üzerine gelen aşındırma tozunun tam olarak dağılamaması gibi etkenler nedeniyle oluklarda yamuk şekiller oluşabilmektedir. Taşın tam olarak disk üzerine temasında taşı diske çeken ağırlığın etkisi önemlidir. Bu nedenle, bu çalışmada ilk olarak GDA deneyi için standartta belirtilen ağırlığın oluk şekli üzerinde ne kadar etkili olduğu üzerinde durulmuş ve GDA deneyi için uygulanan standart sıkıştırma ağırlığ1 olan $14 \mathrm{~kg}$ dışında, $10 \mathrm{~kg}$ ve $18 \mathrm{~kg}$ ağırlıklar da kullanılarak ağırlığın aşınma ve oluk şekli üzerindeki etkileri incelenmiştir. 
Özvan, İnan
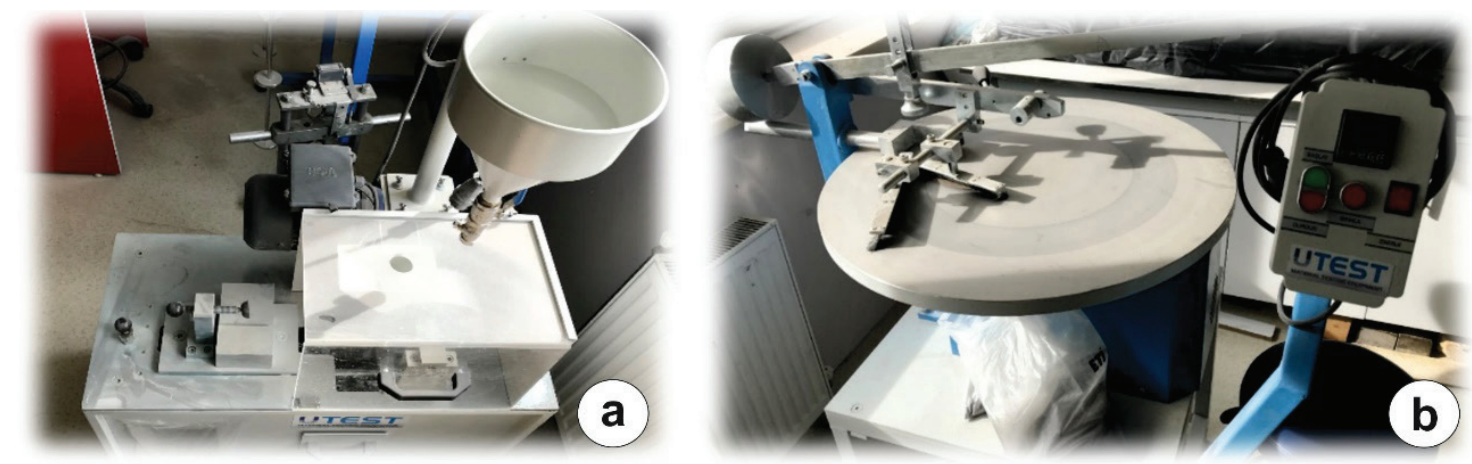

Şekil 3. Geniş Diskli Aşındırma (a) ve Böhme Aşındırma (b) cihazlarına ait bir görüntü.

Figure 3. An image of Wide Wheel Abrasion (a) and Böhme Abrasion (b) devices.

\section{BULGULAR ve TARTIŞMALAR}

\section{Seçilen Kaya Türlerinin Genel Özellikleri}

$\mathrm{Bu}$ çalışmada, bir mermer fabrikasından toplam 4 adet farklı kaya numunesi alınmıştır. Deneye tabi tutulan kayaların üçü kimyasal sedimanter (kireçtaşı) kaya gurubuna, biri ise magmatik kaya (granit) sınıfina aittir (Şekil 4). Sedimanter kayalar makroskobik olarak incelendiğinde bu örneklerin farklı renk, doku ve damar yapısına sahip kireçtaşlarından oluştuğu görülmektedir. Makroskobik ve mikroskobik özelliklerine bakıldığında, Tusba Bej örneği yer yer ayrışmış, yer yer aşırı tektonizma etkisinde kalarak bol kırıklı çatlaklı kaya özelliği kazanmış neritik kireçtaşı olup, çatlaklarında genellikle kalsit dolgu gözlenmektedir. Tamara Bej örneği incelendiğinde, sert, kırılgan bir yapı sunmakta ve bentik foraminifer kavk1 gözlenmektedir. Birim yer yer mikro fosil içermektedir. Rosavera örneği polarizan mikroskop altında incelendiğinde, genelde kalsit mineralinin hakim olduğu ve çatlakların kalsit dolgulu olduğu bir yap1 gözlenmektedir. Diana Granit örneği polarizan mikroskop altında incelendiğinde, kuvars, ortoklas, amfibol, biyotit minerallerinden oluştuğu görülmüştür (Şekil 5).

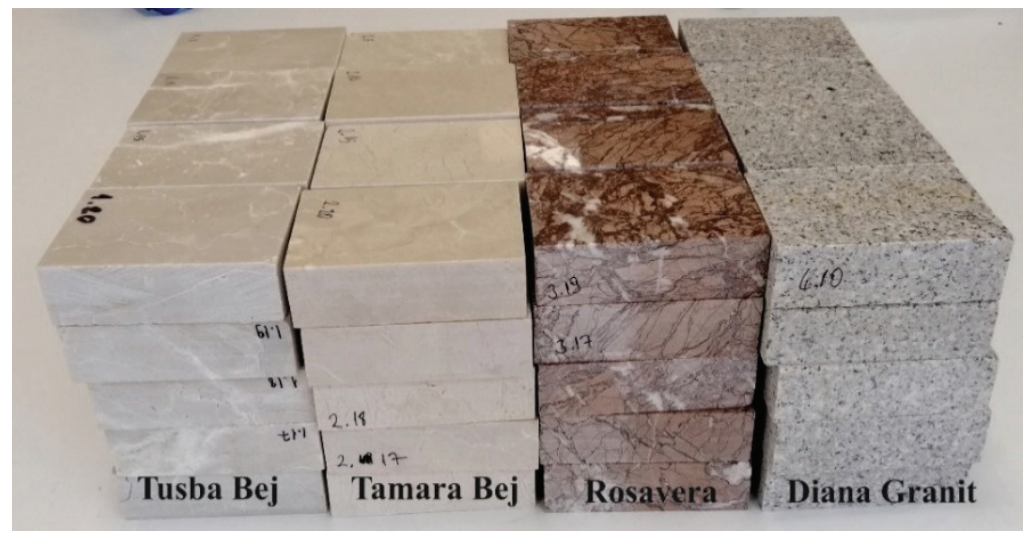

Şekil 4. Çalışmada kullanılan mermer örneklerine ait makroskobik bir görüntü.

Figure 4. A macroscopic view of the marble samples used in the study. 


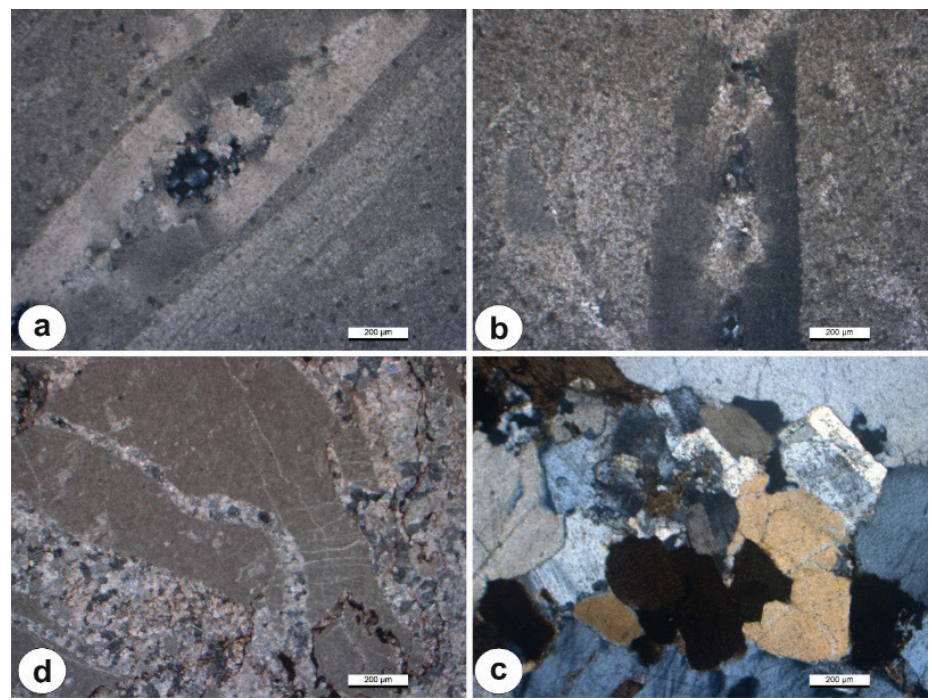

Şekil 5. Çalışmada kullanılan mermer örneklerine ait mikroskobik görüntüler: ((a) Tusba Bej, (b) Tamara Bej, (c) Rosavera, (d) Diana Granit)).

Figure 5. Microscopic views of the marble samples used in the study: ((a) Tusba Bej, (b) Tamara Bej, (c) Rosavera, (d) Diana Granite)).

\section{Seçilen Numunelerin Fiziksel Özellikleri}

$\mathrm{Bu}$ çalışmada, numunelerin fiziksel özelliklerinin belirlenmesi amacıyla 4 ayrı kaya grubunun her birinden 18 adet örnek seçilmiştir. Numunelerin kuru $\left(\gamma_{\mathrm{k}}\right)$ ve doygun $\left(\gamma_{\mathrm{d}}\right)$ birim hacim ağılıkları belirlendikten sonra poroziteleri (n) hesaplanmıştır. Numuneler incelendiğinde, ortalama kuru birim hacim ağırlık (KBHA) değerlerinin $24.86-25.85 \mathrm{kN} / \mathrm{m}^{3}$, doygun birim hacim ağırlı (DBHA) değerlerinin ise $25.04-25.91 \mathrm{kN} / \mathrm{m}^{3}$ arasında değiş̧iği, en düşük KBHA değerinin Diana Graniti, en yüksek KBHA değerinin ise Tusba Bej ile Tamara Bej numunesine ait olduğu belirlenmiştir (Çizelge 1). Numunelerin görünür porozite (n) değerleri incelendiğinde ise, ortalama gözeneklilik değerlerinin \%0.42 ile \%1.81 arasında değiştiği, Diana Graniti'nin gözeneklilik oranının diğer numunelere oranla daha yüksek olduğu tespit edilmiştir (Çizelge 1).
Çalışmanın ilk aşamasında GDA deneyi için standartta belirtilen ağırlığın oluk şekli üzerinde ne kadar etkisi olduğu üzerinde durulmuş ve GDA deneyi için uygulanan standart sıkıştırma ağırlığ ağırlıklar da kullanılarak ağırlığın aşınma ve oluk şekli üzerindeki etkileri incelenmiştir.

GDAdeneyinin sonuçları standartta belirtilen kalibrasyona bağlı olarak hesaplanmaktadır. $\mathrm{Bu}$ nedenle standartta önerilen kalibrasyon mermerinde de üç farklı sıkıştırma yükünde (10 $\mathrm{kg}, 14 \mathrm{~kg}, 18 \mathrm{~kg}$ ), alüminalı erimiş korundum tozu (beyaz) kullanılarak oluklar açılmış ve yüke bağlı oluk değişimleri deney kalibrasyon mermeri olan Boulonnais Mermeri üzerinde de ölçülerek sonuçların kalibrasyonu standarda göre hesaplanmıştır (Çizelge 2). Ayrıca Boulonnais Mermeri üzerinde standartta belirtilen sıkıştırma yükünde siyah renkli yapay korundum aşındırma tozu $14 \mathrm{~kg}$ 'lık yükte denenmiş ve oluşan oluk açıklığ 1 yapılacak hesaplamalarda kullanılmak üzere kaydedilmiştir (Çizelge 3). 
Özvan, İnan

Çizelge 1. Deney tabi tutulan numunelerin ortalama fiziksel özellikleri.

Table 1. Average physical properties of the tested samples.

\begin{tabular}{ccccccc}
\hline \multirow{2}{*}{ Örnek Adı } & & Kuru Kütle (gr) & Yaş Kütle (gr) & KBHA $\left(\mathrm{kN} / \mathrm{m}^{3}\right)$ & DBHA $\left(\mathrm{kN} / \mathrm{m}^{3}\right)$ & $\begin{array}{c}\text { Görünür } \\
\text { Porozite (\%) }\end{array}$ \\
\hline \multirow{3}{*}{ Tusba Bej } & Ortalama & 549.5 & 550.7 & 25.85 & 25.91 & 0.60 \\
& En Büyük & 558.2 & 560.0 & 26.11 & 26.15 & 0.88 \\
& En Küçük & 533.9 & 534.9 & 25.51 & 25.59 & 0.36 \\
\hline \multirow{5}{*}{ Tamara Bej } & Ortalama & 549.0 & 549.9 & 25.79 & 25.83 & 0.42 \\
& En Büyük & 571.7 & 572.8 & 26.03 & 26.07 & 0.59 \\
& En Küçük & 530.5 & 531.3 & 25.47 & 25.51 & 0.29 \\
\hline \multirow{5}{*}{ Rosavera } & Ortalama & 552.3 & 555.0 & 25.54 & 25.66 & 1.26 \\
& En Büyük & 561.5 & 564.3 & 25.91 & 26.02 & 1.98 \\
& En Küçük & 535.8 & 539.6 & 25.06 & 25.24 & 0.71 \\
\hline \multirow{2}{*}{ Diana Graniti } & Ortalama & 530.6 & 534.4 & 24.86 & 25.04 & 1.81 \\
& En Büyük & 552.2 & 556.6 & 25.18 & 25.34 & 2.09 \\
& En Küçük & 509.7 & 513.0 & 24.62 & 24.77 & 1.57 \\
\hline
\end{tabular}

\section{Seçilen Numunelerin Aşınma Direnci Deney Sonuçları}

Boulonnais Mermerinde farklı sıkıştırma yüklerindeki oluk açıklıkları incelendiğinde yükün artmasıyla oluk genişliğinin arttığ1 belirlenmiştir. Ayrıca 14 kg sıkıştırma yükünde beyaz erimiş alümina korundum ile siyah renkli yapay korundum tozu arasında aşındırma farkının hemen hemen aynı olduğu da tespit edilmiştir (Çizelge 2 ve 3 ). Kalibrasyon için önerilen Boulonnais Mermerinde hem farklı tozlar hem de farklı sıkıştırma yüklerinde oluşan oluk açıklıkları değerlendirildiğinde, her iki tozun birbirleri yerine kullanılabileceği ve sıkıştırma yükü arttıkça olukların daha düzgün oluştuğu gözlenmiştir (Şekil 6).
Çizelge 2. GDA deneyinde farklı sıkıştırma yükleri altında alüminalı erimiş korundum tozu (beyaz) kullanıldığında Boulonnais Mermeri üzerinde açılan oluk genişlikleri.

Table 2. Groove widths on the Boulonnais Marble by using aluminized fused corundum powder (white) under different compression loads in GDA experiment.

\begin{tabular}{ccc}
\hline $\begin{array}{c}\text { Deney } \\
\text { No }\end{array}$ & $\begin{array}{c}\text { Uygulanan } \\
\text { sıkş̧tırma yükü } \\
(\mathrm{kg})\end{array}$ & $\begin{array}{c}\text { Boulonnais } \\
\text { Mermeri'nde oluşan } \\
\text { oluk açıklığ }(\mathrm{cm})\end{array}$ \\
\hline 1 & 10 & 1.95 \\
2 & 14 & 2.16 \\
3 & 18 & 2.55 \\
\hline
\end{tabular}

Her sıkıştırma yükünde yapılan GDA deneyi ve elde edilen sonuçlar standartta önerildiği şekilde Boulonnais Mermeri'nden elde edilen düzeltme katsayıları ile kalibre edilmiştir. Ölçülen değer + (20.0 - Kalibrasyon Değeri) eşitliği kullanılarak düzeltilmiş ve Düzeltilmiş Oluk Açıklığı (DOA) (mm) değerleri hesaplanmıştır (Çizelge 4). GDA deneyinde oluk açıklığı standartta önerildiği şekliyle cm cinsinden elde edilmiştir. 
Çizelge 3. GDA deneyinde $14 \mathrm{~kg}$ sıkıştırma yükü altında siyah renkli yapay korundum tozu kullanılarak Boulonnais Mermeri üzerinde açılan oluk genişlikleri.

Table 3. Groove widths on the Boulonnais Marble using artificial corundum powder (black) under $14 \mathrm{~kg}$ compression load in GDA experiment.

\begin{tabular}{ccc}
\hline $\begin{array}{c}\text { Deney } \\
\text { No }\end{array}$ & $\begin{array}{c}\text { Uygulanan } \\
\text { sikıştırma yükü } \\
(\mathrm{kg})\end{array}$ & $\begin{array}{c}\text { Boulonnais } \\
\text { Mermeri'nde oluşan } \\
\text { oluk açıklı̆ } 1(\mathrm{~cm})\end{array}$ \\
\hline 1 & 14 & 2.15 \\
\hline
\end{tabular}

damarlı yapıda olması ve farklı sertliklere sahip minerallerden oluşmasıdır. Özellikle granit içerisinde bulunan kuvars ve feldispat gibi farklı sertliklerdeki mineraller aşınma değerlerini etkilemektedir. Granitte gözlenen bu aşınma farklılığının oluşmasının nedeni, aşındırma tozunun granitteki birincil petrografik değişken olan kuvars yüzdesi içeriğinden etkilenmesidir. Granit gibi farklı sertliğe sahip minerallerden oluşan Boulonnais Mermerindeki oluk açıklığını

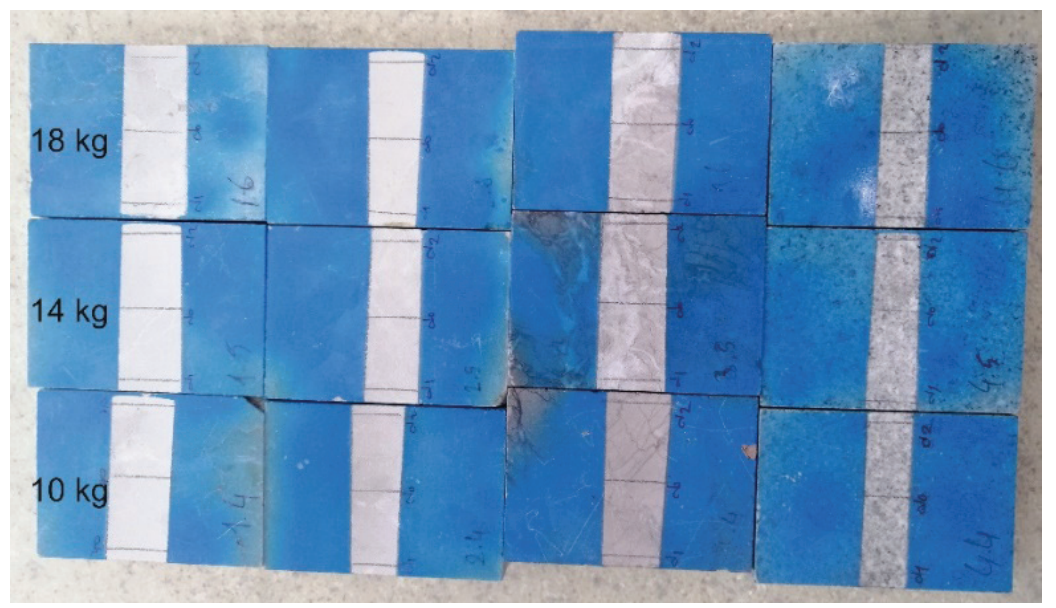

Şekil 6. Farklı sıkıştırma yüklerinde oluşan düzensiz oluk açıklıklarına ait bir görüntü.

Figure 6. An image of the irregular grooves at different compression loads.

Örneklerde ölçülen oluk açıklıkları her sıkıştırma ağırlığı için kıyaslandığında, ağırlık 10 kg'dan 14 kg'a çıkınca oluk açıklığının arttığı, fakat 18 kg'da az da olsa oluk açıklığının azaldığı belirlenmiştir (Şekil 7). Farklı sıkıştırma yüklerinde yapılan GDA deneyi sonuçlarına bakıldığında genelde sıkıştırma yükü arttıkça oluk açıklıklarının da arttığı gözlenmiştir. Fakat DOA değerleri ile sıkıştırma yükü arasında anlamlı bir ilişki gözlenmemiştir. Bunun en büyük nedeni, bu çalışmada kullanılan örneklerin minerallerin etkilediği ve bu etkinin de DOA değerlerine yansıdığı da ayrıca gözlenmiştir. Diana Graniti gibi farklı sertliklere sahip minerallerden oluşan kayaların aşınma değerini modal mineral kompozisyonu kontrol ettiğinden (Yılmaz vd., 2017), bu numunenin düzeltilmiş oluk açıklığı (DOA) değeri farklı sıkıştırma yüklerinde yüke bağlı olarak değişmemiştir. İlerleyen dönemlerde gerçekleştirilecek bilimsel çalışmalarda bu farklılığın detaylarının araştırılması önerilmektedir. 
Özvan, İnan

Çizelge 4. GDA deneyinde farklı sıkıştırma yüklerinden elde edilen ortalama oluk açıklığı değerleri.

Table 4. Average groove gap values obtained from different compression loads in GDA.

\begin{tabular}{lcccccc}
\hline \multirow{2}{*}{ Örnek No } & \multicolumn{2}{c}{$10 \mathrm{~kg}$} & \multicolumn{2}{c}{$14 \mathrm{~kg}$} & \multicolumn{2}{c}{$18 \mathrm{~kg}$} \\
\cline { 2 - 7 } & $\begin{array}{c}\text { Oluk Açıklığı } \\
(\mathrm{cm})\end{array}$ & $\begin{array}{c}\text { Düzeltilmiş̧ } \\
\text { DOA }\end{array}$ & $\begin{array}{c}\text { Oluk Açılığı } \\
(\mathrm{cm})\end{array}$ & $\begin{array}{c}\text { Düzeltilmiş̧ } \\
\text { DOA }\end{array}$ & $\begin{array}{c}\text { Oluk Açıklığı } \\
(\mathrm{cm})\end{array}$ & $\begin{array}{c}\text { Düzeltilmiş } \\
\text { DOA }\end{array}$ \\
\hline Tusba Bej & 1.82 & 1.87 & 2.18 & 2.02 & 2.46 & 1.91 \\
Tamara Bej & 1.64 & 1.69 & 1.84 & 1.68 & 2.00 & 1.45 \\
Rosavera & 1.88 & 1.93 & 2.11 & 1.95 & 2.47 & 1.92 \\
Diana Graniti & 1.51 & 1.56 & 1.81 & 1.65 & 1.97 & 1.42 \\
\hline
\end{tabular}

Ortalama oluk açıklıkları seçilen örnekler üzerinden değerlendirildiğinde en fazla aşınan malzemenin Tusba Bej ticari ismi ile anılan kaya numunesi olduğu, en az aşınan kaya numunesinin ise Diana Graniti ticari ismi ile anılan kaya olduğu belirlenmiştir. Görsel olarak birbirine benzeyen Tusba Bej ile Tamara Bej örnekleri arasında aşınma kaybı miktarı açısından ciddi bir fark olduğu görülmüştür. $\mathrm{Bu}$ sonuçlar değerlendirildiğinde, hem makroskobik hem de mikroskobik olarak kalsit damarlı olan Tusba Bej ve Rosavera örneklerinin aşınmadan daha fazla etkilendiği görülmüştür. Örneklerin porozite değerleri ile aşınma değerleri karşılaştırıldığında aşınma miktarı ile örneğin gözeneği arasında bir ilişkinin olmadığı da belirlenmiştir. Özellikle anizotrop özelliğe sahip kayalarda aynı numunenin farklı yerlerinde farklı oluk açıkları oluşmaktadır. Bu nedenle GDA deneyinin anizotropi özelliği gösteren kayalarda yapılmasının yanlış sonuçlar doğurabileceği ortaya çıkmaktadır.

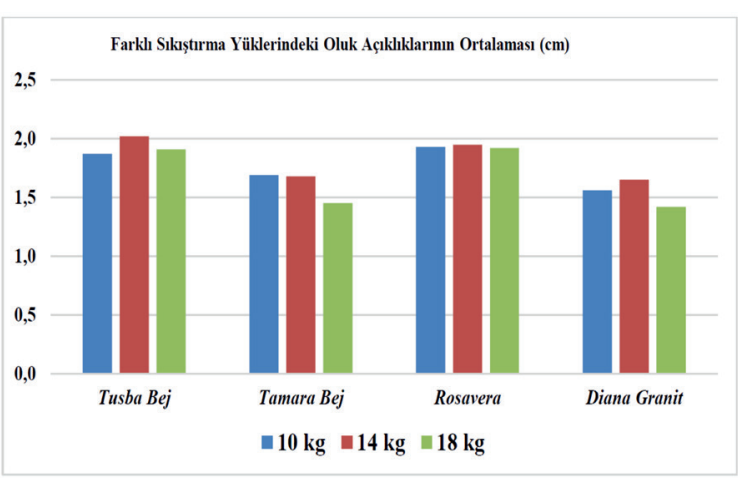

Şekil 7. Farklı sıkıştırma yüklerinde oluşan düzeltilmiş oluk açıklıklarına (DOA) ait ortalama değerleri gösteren bar diyagramı.

Figure 7. Bar diagram showing the mean values of the calibration groove aperature (DOA) formed at different compression loads.

$\mathrm{Bu}$ çalışmada GDA deneyinin uygulandığ mermer örneğinin yüzeyinin cilalı olup olmadığ 1 ayrıca incelenmiştir. Bilindiği üzere, bu gibi deneyler yapilırken bazen ocaktan bazen de fabrikadan laboratuvara örnekler nakledilebilmektedir. Ticari anlamda kullanılan mermerlerin genelde bir yüzeyi cilalanmaktadır. $\mathrm{Bu}$ duruma sahip mermerlerde oluşan aşınma kayb1 değerlerinin belirlenmesi için GDA deneyi standartta belirtildiği şekliyle $14 \mathrm{~kg}$ sıkıştırma yükünde yapılmıştır. GDA deneyleri seçilen örneklerin hem cilalı yüzeylerinde hem 
de yapıştırmada kullanılacak mat yüzeylerinde ayrı ayrı uygulanmıştır. Deney sonuçlarına bakıldığında cilalı yüzeylerdeki oluk açıklığ1 miktarının mat yüzeylerde oluşan oluk açıklığ1 miktarına göre daha az olduğu görülmüştür (Şekil 8). Bunun nedeni cilalı yüzeydeki cila tabakasının aşınma miktarını etkilemesidir. $\mathrm{Bu}$ nedenle sonuçların daha doğru yorumlanmasında işlem görmemiş mat yüzeylerde deneyin yapılması önerilmektedir.

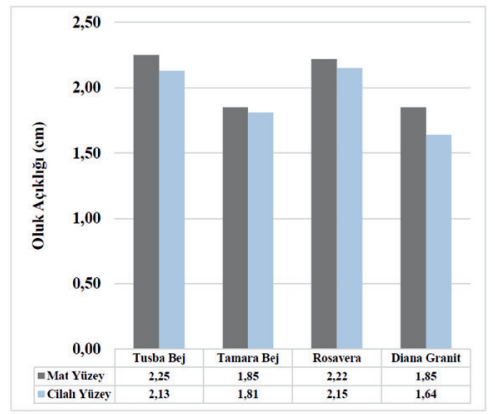

Şekil 8. Mat ve cilalı yüzeylerde uygulanan GDA deney sonuçlarının ortalamalarına ait bar diyagramı.

Figure 8. Bar diagram of the average values of the GDA test results applied on the matte and polished surfaces.

GDA deneyinde beyaz erimiş alümina korundum aşındırıcı tozun, yapay korundum aşındırıcı toza göre aşındırmayı daha fazla gerçekleştirdiği tespit edilmiştir (Çizelge 5 Şekil 9). Toplamda 48 örnek üzerinde her iki toz ile yapılan deneylerde oluk açıklığı tespit edilmiş ve ortalama olarak Şekil 9'daki değerler elde edilmiştir. Oluşan oluk açıklıklarına bakıldığında Tusba Bej ile Rosavera mermer örneklerinde her iki toz kullanıldığında aşındırma miktarı $2 \mathrm{~cm}$ 'den fazla iken, diğer iki örnekte ise 2 cm'nin altında değerler elde edilmiştir. Her iki aşındırma tozundan elde edilen değerler arasında korelasyon ilişkisine bakıldığında yüksek belirleme katsayısına $\left(\mathrm{R}^{2}=0.89\right)$ sahip bir ilişki belirlenmiştir (Şekil 10). İki farklı aşındırma tozunun GDA deneyinde birbiri yerine kullanılması durumunda çok büyük farkların olmayacağ 1 ve Eşitlik 1'de önerilen formül ile bu farklılığın giderilebileceği ortaya konmuştur.

$\mathrm{ST}=0.8786^{*} \mathrm{BT}^{1.1162}$

$\mathrm{Bu}$ eşitlikte;

ST: Siyah renkli yapay korundum tozu kullanılarak yapılan GDA deneyi $(\mathrm{cm})$

BT: Beyaz erimiş alümina korundum tozu kullanılarak yapılan GDA deneyi $(\mathrm{cm})$

Çizelge 5. İki farklı aşındırıcı toz ile elde edilen oluk açıklığ ortalama değerleri.

Table 5. Average groove values obtained with two different abrasive powders.

\begin{tabular}{lcc}
\hline Örnek No & $\begin{array}{c}\text { Siyah renkli } \\
\text { yapay } \\
\text { korundum (ST) }\end{array}$ & $\begin{array}{c}\text { Beyaz erimiş } \\
\text { alümina } \\
\text { korundum (BT) }\end{array}$ \\
\hline Tusba Bej & 2.16 & 2.18 \\
Tamara Bej & 1.75 & 1.84 \\
Rosavera & 2.09 & 2.11 \\
Diana Graniti & 1.86 & 1.81 \\
\hline
\end{tabular}

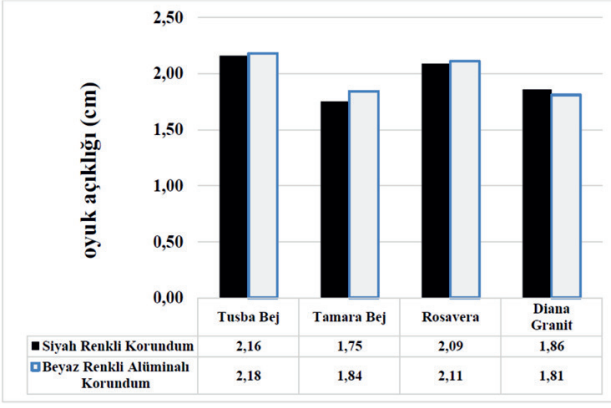

Şekil 9. İki farklı aşındırıcı toz ile yapılan GDA deneyi sonuçları (14 kg'lık sıkıştırma yükünde).

Figure 9. GDA test results using two different abrasive powders (14 kg compression load). 


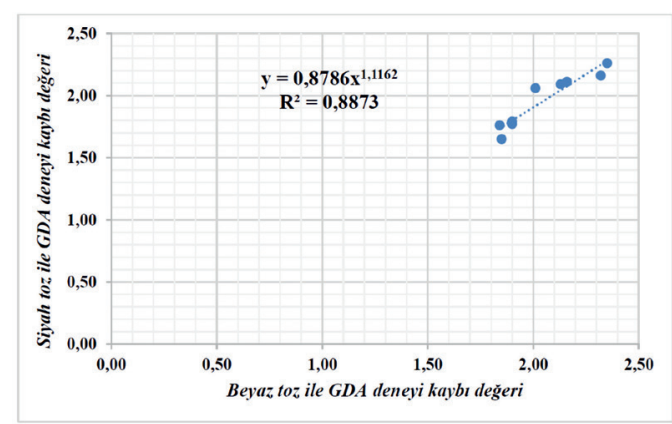

Şekil 10. GDA deneyinde farklı tozlardan elde edilen aşınmalar arasındaki korelasyon ilişkisi.

Figure 10. Correlation relationship between abrasions obtained from different powders in the GDA test.

GDA deney sonuçlarının karşılaştırılması amacıyla yapılan BA deneyinde ise, aşınma miktarı standartta önerildiği şekliyle $\mathrm{cm}^{3} / 50 \mathrm{~cm}^{2}$ cinsinden elde edilmiştir. Bu çalışmada kullanılan numunelerin BA değerlerine bakıldığında genel olarak en az aşınan numunelerin GDA sonuçlarında olduğu gibi Diana Graniti ve Tamara Bej mermeri olduğu görülmüştür. İki farklı aşındırma tozu ile yapılan deneyde GDA deneyinde olduğu gibi benzer sonuçlar elde edilmiştir. Toplamda 24 örnek üzerinde her iki toz ile oluşan aşındırma miktarı test edilmiş ve ortalama olarak Şekil 11'deki değerler elde edilmiştir. Aşındırma miktarına bakıldığında, Tusba Bej mermeri ile Rosavera mermeri örneklerinde her iki toz arasındaki aşındırma miktarlarında \%1'den az bir fark bulunurken, diğer iki örnekte ise \%1 ile 2 arasında bir fark oluştuğu görülmüştür (Şekil 11).

Her iki aşındırma tozundan elde edilen değerler arasındaki korelasyon ilişkisine bakıldığında yüksek belirleme katsayısına $\left(\mathrm{R}^{2}=0.99\right)$ sahip bir ilişkinin elde edildiği belirlenmiş olup (Şekil 12), bu iki aşındırma tozunun BAdeneyinde birbiri yerine kullanılması durumunda çok büyük farkların olmayacağı ve Eşitlik 2'de önerilen formül ile bu farklıllı̆̆n giderilebileceği ortaya konmuştur.

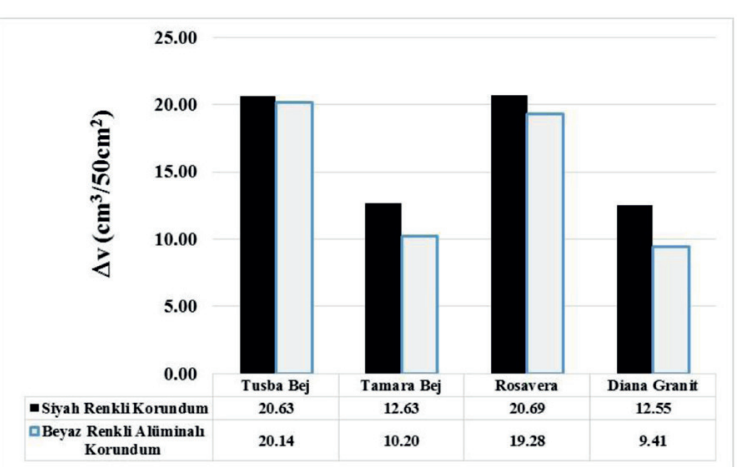

Şekil 11. İki farklı aşındırıcı toz ile yapılan BA deneyi sonuçları.

Figure 11. BA test results using two different abrasive powders.

$\mathrm{ST}=2.5549 * \mathrm{BT}^{0.7}$

Bu eşitlikte;

ST: Siyah renkli yapay korundum tozu kullanılarak yapılan BA deneyi $\left(\mathrm{cm}^{3} / 50 \mathrm{~cm}^{2}\right)$

BT: Beyaz erimiş alümina korundum tozu kullanılarak yapılan BA deneyi $\left(\mathrm{cm}^{3} / 50 \mathrm{~cm}^{2}\right)$

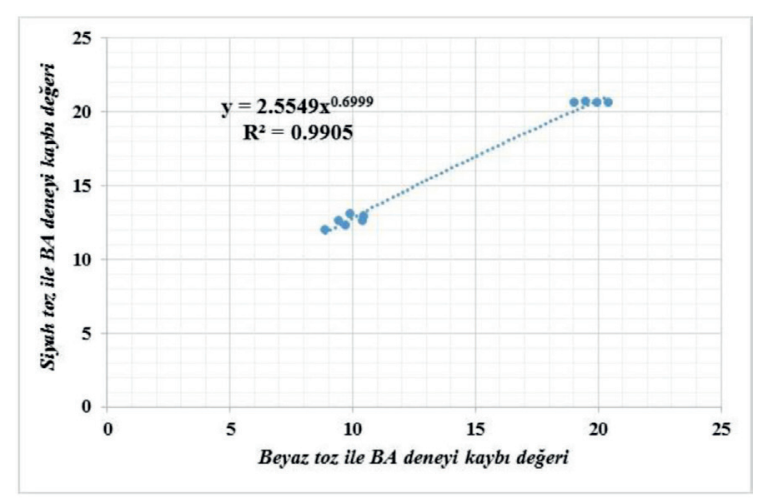

Şekil 12. BA testinde farklı tozlardan elde edilen aşınmalar arasındaki korelasyon ilişkisi.

Figure 12. Correlation relationship between abrasions obtained from different powders in the BA test. 


\section{SONUÇLAR ve ÖNERÍLER}

Bu çalışmada kayaların aşındırılmasında son yıllarda sıkça kullanılan Geniş Diskli Aşındırma (GDA) deneyinde karşılaşılan sorunlar farklı yöntem ve malzeme ile irdelenmiştir.

GDA deneyinde, karşı sıkıştırma ağırlığının artmasıyla aşınma miktarının arttığı ve ağırlığın azaltılmasıyla da oluk açıklığının yamuk bir şekil aldığı görülmüştür. Fakat DOA değerleri hesaplandığında, sıkıştırma yükünün artmasıyla oluk açıklığının artmadığı belirlenmiştir. Bunun en büyük nedeni, bu çalışmada kullanılan örneklerin damarlı yapıda olması ve farklı sertliklere sahip minerallerden oluşmasıdır. Özellikle granit içerisinde bulunan kuvars ve feldispat gibi farklı sertliklerdeki mineraller aşınma değerlerini etkilemektedir.

$\mathrm{Bu}$ çalışmada kullanılan kayaların GDA ve BA sonuçlarına bakıldığında, genel olarak en az aşınan örneğin Diana Graniti olduğu belirlenmiştir. Granit türü kayaçlarda Boulonnais Mermeri'ndeki oluk açıklığının minerallerin sertliğinden etkilenebileceği düşünüldügünden, GDA deneyi sonrasında hesaplanan düzeltilmiş oluk açıklığı (DOA) değerlerinde hatalar olabileceği gözlenmiştir. Gerçekleştirilecek bilimsel çalışmalarla bu farklılığın nedenlerinin araştırılması önerilmektedir.

GDA deneyindeki oluk açıklığ örneğin farklı yerlerindeki gözeneklilik, bantlı yap1, fosil içeriği gibi anizotrop özelliklerden etkilendiği için değerlendirmelerde bazen doğru sonuçlar verememektedir. Bu nedenle deneye tabi tutulacak örneklerde aşındırılacak yüzeyin numunenin tümünü yansitmasına dikkat edilmelidir. Ayrıca deney esnasında fiziksel ortamın ve kayaç ile aşındırıcı disk arasına akış sağlayan huninin eğikliği aşınma sırasında oluşan oluk şekillerinin kısmen farklılık göstermesine sebep olduğu gözlenmiştir. BA deneyi, kayacın tüm yüzeylerinde 16 farklı döngü ve her bir döngüde $90^{\circ}$ çevrilerek gerçekleştirildiğinden kayacın dokusu, mineralojik yapısı, bileşenlerinin dizilimi gibi anizotropi etkisi k1smen giderilmektedir. $\mathrm{Bu}$ nedenle anizotrop özellik gösteren kaya örneklerinde GDA deneyi yerine BA deneyi ile aşındırma kaybının belirlenmesi önerilmektedir.

GDA deneyinde 4 farklı örneğe ait cilalı ve mat yüzlerin aşındırma kayıpları irdelendiğinde, deneye tabi tutulan tüm örneklerde mat yüzlerin daha iyi aşındığ 1 belirlenmiştir. Cilalı yüzlere ait örneklerin cila sertliğine bağlı olarak aşınmaya karşı daha dirençli oldukları tespit edilmiştir. $\mathrm{Bu}$ nedenle deneye tabi tutulacak örneklerin doğal yüzeylerinde deneyin yapılması önerilmektedir.

İki farklı aşındırıcı toz ile aynı örnekler üzerinde yapılan deneyler sonucunda, GDA deneyi için standartlara uygun olarak kullanılan beyaz erimiş alümina korundum aşındırıcının kısmen siyah renkli yapay korundum aşındırıcı toza göre örnekleri daha fazla aşındırdığı tespit edilmiştir. BA deneyinde ise, standartlarda belirtilen siyah renkli yapay korundum tozun beyaz erimiş alümina korundum toza nazaran örneklerde \%1-2 oranında daha fazla aşınma kaybına neden olduğu belirlenmiştir.

Deneyler sonucunda her iki aşındırıcı tozun sonuçları GDA deneyi için karşılaştırıldığında;

- Her iki tozun aşındırma sonuçları arasında çok az farkın olduğu, bu tozların birbirleri yerine kullanılabileceği belirlenmiştir.

- GDA testi için standartlarda belirlenen beyaz erimiş alümina korundum aşındırıcı toz ile deney yapilırken toz sarfiyatının yaklaşık 2500 gr olduğu, siyah renkli yapay korundum tozu ile aynı deneyin yaklaşık 1400 gr ( \pm 50$)$ ile yapıldığ 1 tespit edilmiştir. 
Özvan, İnan

- Tane boyu 80 olan beyaz erimiş alümina korundum aşındırıcı tozun üç deneyde kullanılabilmesine karşın, tane boyu 200 olan siyah renkli yapay korundum aşındırıcı tozun her deney sonrası 20 gr $( \pm 5)$ azaldığ 1 ve azalan gramaj miktarı dahi göz önüne alındığında siyah renkli yapay korundum tozun daha çok test için kullanılabileceği belirlenmiştir.

Aşındırıcı tozların bu sonuçları yorumlanacak olursa, siyah renkli yapay korundum aşındırıcı tozun, beyaz erimiş alümina korundum toza göre tek dezavantajının maliyeti olduğu belirlenmiştir. Fakat kullanım sıklığı ve deneye tabii tutulan miktar göz önünde bulundurulduğunda siyah renkli yapay korundum tozunun GDA deneylerinde kullanımının teknik ve ekonomik açıdan mümkün olabileceği belirlenmiştir.

\section{KAYNAKLAR}

Çobanoğlu, İ., Çelik, S.B., 2010. Correlation between wide whell abrasion (capon) and Böhme abrasion test results for some carbonate rock. Sci.Res. Essays, 5, (22), 3398-3404.

Çobanoğlu, İ., Çelik, S.B., 2017. Assessments on the usability of Wide Wheel (Capon) test as reference abrasion test method for building stones. Construction and Building Materials, 151, 319-330.
Karaca, Z., Deliormanli, A.H., Elçi, H., Pamukcu, C., 2010. Effect of freeze-thaw process on the abrasion loss value of stones. International Journal of Rock Mechanics and Mining Sciences, 47(7), 1207-1211.

Karaca, Z., Yılmaz, N.G., Göktan R. M., 2012. Considerations on the European Standard EN 14157 test methods: abrasion resistance of natural stones used for flooring. Rock Mechanics and Rock Engineering, 45, 103-111.

McGregor, I.D., Chiu, K.Y., 2000. Porosity and wear resistance in stone flooring. Journal of Test Evaluation, 28, 149-154.

Marini, P., Bellopede, R., Perino, L., Regibus, C.D. 2011. Optimisation of an abrasion resistance test method on natural stones. Bulletin of Engineering Geology and the Environment, 70, 133-138.

Sahlin, T., Starzec, K., Stigh, J., Schouenborg, B., 2001. Physical properties and durability of fresh and impregnated limestone and sandstone from central Sweden used for thin stone flooring and cladding. 9th International Congress on Deterioration and Conservation of Stone, 19-24 June 2000, Venice. 181-185.

TS 699, 2016. Tabii Yapı Taşları, İnceleme ve Laboratuvar Deney Yöntemleri. Türk Standartları Enstitüsü, Ankara. 36.

TS EN 14157, 2017. Doğal taşlar - Aşınma direncinin tayini. Türk Standartları Enstitüsü, Ankara. 21.

Yilmaz, NG., Goktan, R.M., Onargan, T., 2017. Correlative relations between three-body abrasion wear resistance an petrographic properties of selected granites used as floor coverings. Wear, 372-373, 197-207. 